\title{
Pulmonary metastasectomy in pediatric patients
}

\author{
${\text { Basak Erginel }{ }^{1 *}, \text { Feryal Gun Soysal }^{1,2}, \text { Erbug Keskin }^{1}, \text { Rejin Kebudi }}^{2}$, Alaaddin Celik ${ }^{1}$ and Tansu Salman ${ }^{1}$
}

\begin{abstract}
Background: This study aims to evaluate the outcomes of pulmonary metastasectomy resections in pediatric patients. Methods: We retrospectively reviewed the medical records of 43 children who were operated on in the Pediatric Surgery Clinic between January 1988 and 2014. Forty-three children (26 boys; 17 girls; mean age $10 \pm 4.24$ years, range 6 months-18 years) who underwent pulmonary metastasectomy resection were included in the study. The patients were evaluated based on age, gender, history of disease, surgical procedures, complications, duration of hospitalization, duration of chest tube placement, and procedure outcome.
\end{abstract}

Results: Indications for pediatric resections were oncological. Metastasis was secondary to Wilms' tumor in 14 patients, osteosarcoma in 7 patients, Ewing's sarcoma in 5 patients, rhabdomyosarcoma in 5 patients, lymphoma in 3 patients, hepatoblastoma in 2 patients, and other tumors in 7 patients. A total of 59 thoracotomies were performed. Approaches utilized included unilateral posterolateral thoracotomy $(n=33)$, bilateral posterolateral thoracotomy $(n=8)$, and sternotomy $(n=2)$. Wedge resection was the procedure of choice $(n=44)$. In selected cases, 11 segmentectomies, 3 lobectomies, and 1 pneumonectomy were performed. There was no perioperative mortality. One patient suffered prolonged air leak and three patients from fever. All patients received chemotherapy. Radiotherapy was administered to 16 patients (37.2\%). Of those 16 patients, 7 had Wilms' tumor, 6 had Ewing's sarcoma/PNET, and 3 were rhabdomyosarcoma patients. During a median follow-up of 3 years, the overall survival was $74.4 \%$.

Conclusions: Multidisciplinary treatment involving pediatric oncologists, surgeons, and radiation oncologists is necessary to obtain positive results in children who have pulmonary metastases of oncological diseases.

Wedge resection is a suitable option for children because less lung tissue is resected.

Keywords: Pulmonary, Pediatric, Metastasectomy, Pulmonary metastasectomy, Pediatric surgery

\section{Background}

Surgical excision is the gold standard in the pediatric metastases of pediatric age tumors. The loss of lung parenchyma and blood is important as it causes an increase in postoperative complications and morbidity [1]. Surgical excision is necessary to preserve the maximum amount of lung parenchyma but avoid local recurrence of disease. There is limited data in the literature concerning pulmonary metastasectomies in children. The purpose of our study is to evaluate our pediatric oncological patients who underwent pulmonary resections for metastases.

\footnotetext{
* Correspondence: basakerginel@hotmail.com

${ }^{1}$ Istanbul Faculty of Medicine, Department of Pediatric Surgery, Istanbul University, Oguz Goker Caddesi, 5. Gazeteciler Sitesi, C-1 Blok No. 36, Akatlar Mahallesi, Besiktas, Istanbul, Turkey

Full list of author information is available at the end of the article
}

\section{Methods}

Between 1988 and 2014, 43 children underwent surgery for pulmonary metastasectomy for oncological diseases at the Department of Pediatric Surgery. Indications of successful lung metastasectomy consisted of achieving control of the primary disease and observing the presence of sufficient lung capacity, as reported in the literature, in the patients $[2,3]$. A pediatric hematology and oncology committee-including pediatric oncologists, pediatric surgeons, pediatric radiologists, and pediatric radiation oncologists-decides and assigns the indication for each lung metastasis.

The medical records of 43 children were retrospectively evaluated based on age, gender, history of disease, surgical procedure, complications, duration of 
hospitalization, duration of chest tube placement, and procedure outcome.

All statistical analyses were carried out with SPSS 22.0 (IBM, USA). Statistical significance was defined as $p<0.05$.

\section{Results}

Forty-three children were included in the study (26 boys; 17 girls), with a mean age of $10 \pm 4.24$ years (range 6 months -18 years). There was no statistically significant difference between the age and gender of the patients and overall survival rates $(p=0.029$ and $p=0.48$, respectively).

Thirty-two patients $(74.4 \%)$ had no symptoms. Fever $(9.3 \%)$ and fever with cough $(9.3 \%)$ were the next most common presentations. Chest radiography is performed in all patients. Thoracic computerized tomography (CT) was performed in all of the patients, and PET CT was performed in five patients.

All pediatric pulmonary resections were performed due to oncological diseases. The most frequent indication was pulmonary metastasis of Wilms' tumor $(32.5 \%)$ in 14 patients. Other common causes of metastasis were osteosarcoma in 7 patients (16.2\%), Ewing's sarcoma in 5 patients (11.6\%), rhabdomyosarcoma in 5 patients (11.6\%), lymphoma in 3 patients (6.9\%), and hepatoblastoma in 2 patients (4.6\%). Less common reasons were fibrosarcoma, PNET, neuroblastoma, teratoma, clear cell carcinoma, adrenal carcinoma, and testicular embryonal carcinoma, existing in one patient $(2.3 \%)$ (Table 1$)$.

Left thoracotomy was performed in 21 patients, right thoracotomy was performed in 12 patients, bilateral thoracotomy was performed in 8 patients, and sternotomy was performed in 2 patients (Fig. 1).

In terms of surgery, 44 wedge resections, 11 segmentectomies, 3 lobectomies, and 1 pneumonectomy were performed (Fig. 2). Wedge resections (74.5\%) were performed more frequently than anatomic resections (segmentectomy, lobectomy, pneumonectomy) (25.5\%).

Eleven $(25.5 \%)$ patients underwent more than one thoracotomy. Six of those underwent two thoracotomies (three with Wilms' tumor, two with osteosarcoma, and one with Ewing's sarcoma). Five of the 11 patients who received a rethoracotomy were operated on three times (three patients with osteosarcoma, two with Wilms' tumor). In total, 59 thoracotomies were performed on 43 patients There was a statistically significant correlation between the number of recurrent thoracotomies in a patient and his/her survival $(p=0.005)$. It is likely to assume that patients in this group are in the advanced stages of the malignancy and thus they are receiving repeated thoracotomies.

The median number of resected nodules was $2(1-17)$.
Table 1 Clinical features of the children

\begin{tabular}{lll}
\hline & Number & Percent \\
\hline Gender & 26 & \\
Male & 17 & 60.5 \\
Female & & 39.5 \\
Complaints & 32 & \\
None & 4 & 69.7 \\
Fever & 3 & 9.3 \\
Cough & 4 & 6.9 \\
Fever + cough & & 9.3 \\
History of disease & 14 & \\
Wilms' & 7 & 32.5 \\
Osteosarcoma & 5 & 16.2 \\
Ewing & 5 & 11.6 \\
Rhabdomyosarcoma & 3 & 11.6 \\
Lymphoma & 2 & 6.9 \\
Hepatoblastoma & 1 & 4.6 \\
Fibrosarcoma & 1 & 2.3 \\
PNET & 1 & 2.3 \\
Neuroblastoma & 1 & 2.3 \\
Teratoma & 1 & 2.3 \\
Clear cell carcinoma & 1 & 2.3 \\
Adrenal carcinoma & & \\
Testis fibrosarcoma & & \\
\hline
\end{tabular}

The mean length of hospitalization was 5.1 days. There was no perioperative mortality. We had no perioperative or postoperative complications, with the exception of fever in three patients and prolonged air leak in one patient.

A complete surgical resection with negative margins in the pathological reports was assessed in all of the patients.

After the early postoperative period, each patient was re-evaluated by the pediatric hematology and oncology committee to determine the appropriate postoperative adjuvant treatment. All patients received chemotherapy. Radiotherapy was administered to 16 patients (37.2\%). Of those 16 patients, seven had Wilms' tumor, six had Ewing's sarcoma/PNET, and three were rhabdomyosarcoma patients. During a median follow-up of 3 years, the overall survival was $74.4 \%$. Table 2 summarizes the percentage of survival among our 43 patients during a median follow-up period of 3 years (range 1-5 years). Survival analysis for each cancer type is given in Table 2. After pulmonary metastasectomy, the 3-year survival rate for Wilms' tumor was 12/14 (85\%), osteosarcoma was 2/ 7 (28 \%), Ewing's sarcoma was 5/5 (100\%), rhabdomyosarcoma was $3 / 5$ (60 \%), lymphoma was $3 / 3$ (100\%), and hepatoblastoma was 1/2 (50\%). 


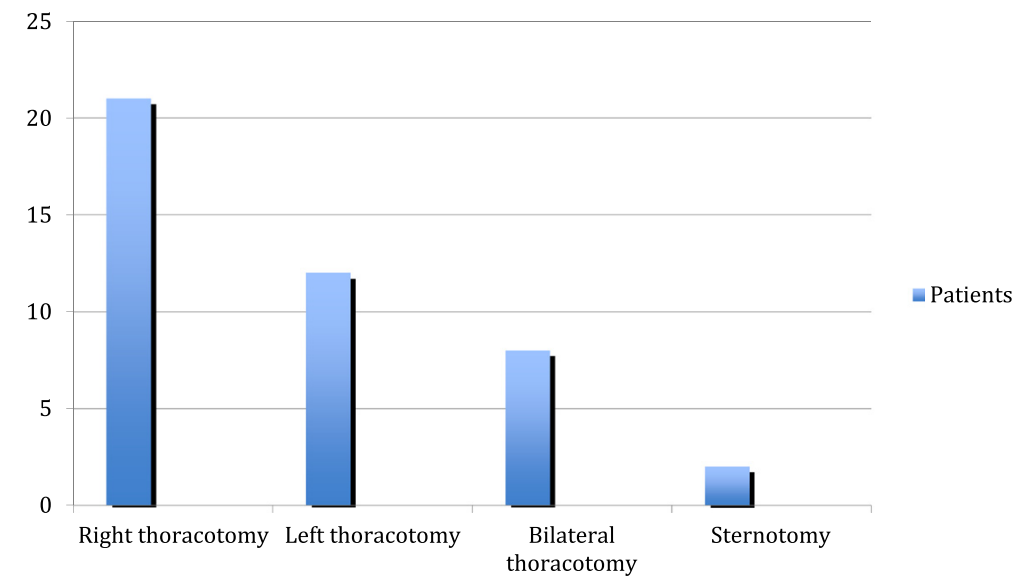

Fig. 1 Our surgical approaches for pulmonary metastases

\section{Discussion}

In children with solid tumors, the most common metastatic site is the lungs. Only a few decades ago, the survival of a child with cancer was very short when thoracic metastases were detected. However, with advances in CT technology, detection of even millimetric nodules is possible, and an improved understanding and recognition of the indications for surgical intervention has enabled these patients to survive much longer. In the literature, pulmonary metastasectomy is the part of standard treatment for adults with metastasis, but the data regarding surgical management of metastatic pulmonary nodules in children remains limited [4]. Success in prolonging patient survival rate via pulmonary metastasectomy is proven, particularly by retrospective studies involving osteosarcoma patients [5]. Incomplete resection is associated with short survival. In a series of studies by Tronc et al. evaluating 52 children with pulmonary nodules, four patients with incomplete resections died rapidly during the follow-up period [3]. In this study, pediatric oncology patients who underwent pulmonary resection for oncological metastatic nodules in our clinic are evaluated retrospectively. None of the resections involves primary pulmonary mediastinal mass.

Parida et al. evaluated 37 children with osteosarcoma and other cancers, for whom they performed thoracoscopic pulmonary metastasectomy after CT-guided needle hook replacement. They stated that thoracoscopic resection in preoperatively localized lung nodules is both a safe and efficient alternative to open surgery [6]. Han et al. evaluated 105 patients with pulmonary metastasectomy. They compared their thoracotomies $(n=46)$ and thoracoscopies $(n=62)$, which were undertaken to manage solitary lung metastases. They found that thoracoscopic metastasectomy is a promising option in small solitary pulmonary metastases [7]. One of the limitations of the study is the relatively small patient number, as is the study's retrospective design. However, our morbidity and mortality are very low. One of the advantages of our open approach is that it permits palpation. CT scans

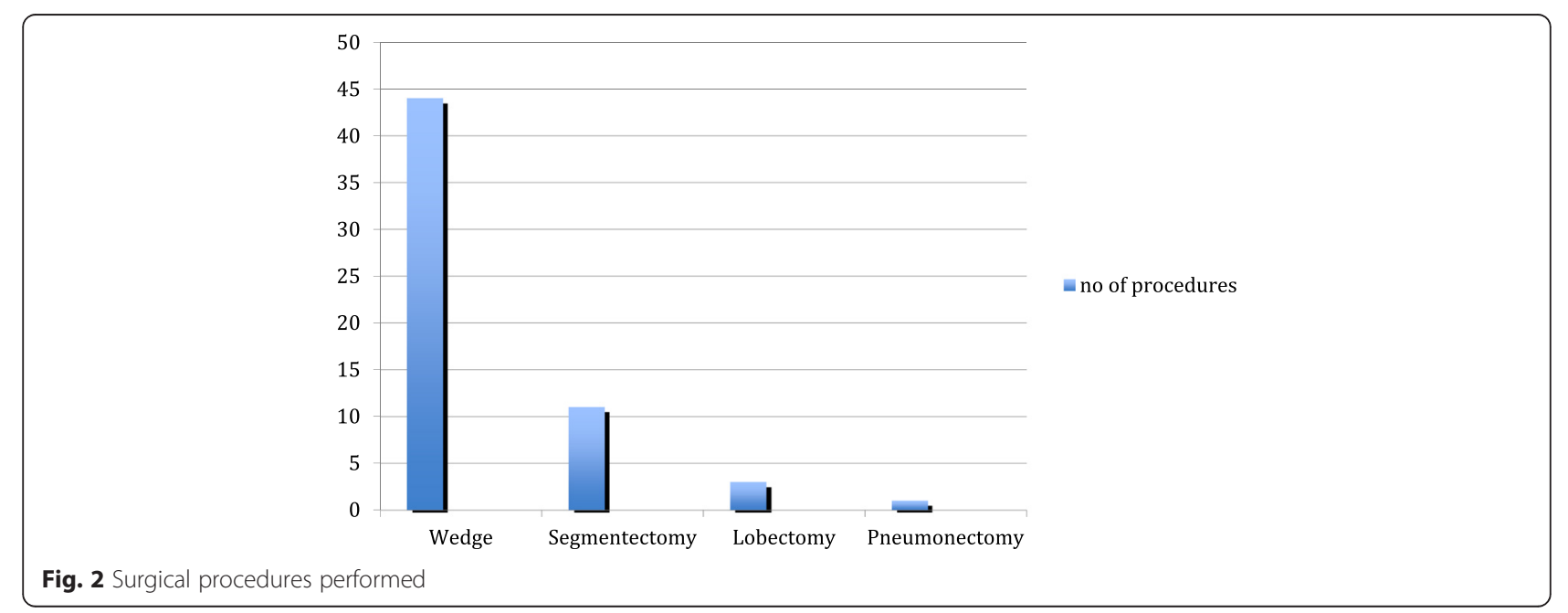


Table 2 Long-term (3-year) survival after pulmonary resection

\begin{tabular}{lll}
\hline & Number & Survivors \\
\hline Wilms' & 14 & $12 / 14(85 \%)$ \\
Osteosarcoma & 7 & $2 / 7(28 \%)$ \\
Ewing & 5 & $5 / 5(100 \%)$ \\
Rhabdomyosarcoma & 5 & $3 / 5(60 \%)$ \\
Lymphoma & 3 & $3 / 3(100 \%)$ \\
Hepatoblastoma & 2 & $1 / 2(50 \%)$ \\
Fibrosarcoma & 1 & $1 / 1(100 \%)$ \\
PNET & 1 & $1 / 1(100 \%)$ \\
Neuroblastoma & 1 & $1 / 1(100 \%)$ \\
Teratoma & 1 & $1 / 1(100 \%)$ \\
Clear cell carcinoma & 1 & $1 / 1(100 \%)$ \\
Adrenal carcinoma & 1 & $0 / 1(0 \%)$ \\
Testis fibrosarcoma & 1 & $1 / 1(100 \%)$ \\
Total & 43 & $32 / 43(74.4 \%)$ \\
\hline
\end{tabular}

sometimes underestimate the number of metastases [8]. The location of the metastatic nodule is also an important factor effecting predictive outcomes. Centrally located lesions may require anatomical resections such as lobectomy instead of the more common wedge resections performed for peripheral lesions. Letourneau et al. reported a very poor prognosis in patients with centrally located metastases in a retrospective evaluation of 115 osteosarcoma patients with pulmonary metastases [9].

Various prognostic factors are investigated to determine the effect of pulmonary metastasectomy on overall survival [10]. Optimal timing is also important in pulmonary metastasectomy as determined by Tanaka et al. A short interval between the detection of the tumor and pulmonary metastasectomy causes early relapses, according to their study [11].

We chose a second thoracotomy for our bilateral tumor cases rather than the bilateral simultaneous approach [12] utilized by Torre et al. In only two of our cases did we choose to perform a sternotomy incision and bilateral metastasectomy.

We prefer to perform lung sparing surgeries as much as possible, but it is also important to excise appropriate margins in order to avoid tumor recurrence. In most patients, a non-anatomic resection (wedge resection) was sufficient to adequately excise the tumor $(44 / 59)$. Sublobar resections consisting of either segmentectomies or wedge resections are suitable surgical techniques to excise a pulmonary nodule, as they allow for the preservation of lung function in a growing child and avoid blood loss in smaller patients. We utilized sublobar resection in 55 of $59(93.2 \%)$ cases. As stated in the study performed by Döngel et al., sublobar resections are a suitable option for pediatric pulmonary metastasectomy [1].
There exists limited study data in the literature on long-term outcomes following pulmonary metastasectomy for removal of metastases secondary to solid tumors. Abel et al. evaluated the long-term survival of 20 children who underwent pulmonary metastasectomy. They suffered one early postoperative loss due to pneumonia, and four patients died later due to late metastases (mean of 29 months later). The overall mortality of their series was $25 \%$ [12]. Hacker et al. evaluated 10 pulmonary metastasectomy patients, and during a mean follow-up period of 49 months, 8 patients (80 \%) remained in complete remission [13]. Among our 43 pulmonary metastasectomy patients, there were 11 deaths, and our overall mortality was $11 / 43$ (25.5\%), a percentage similar to the findings of their study.

Kayton et al. reported on their 50 years of cumulative experience performing metastasectomies in the pediatric population and established that pediatric pulmonary metastasectomy may be performed safely and effectively [14].

The present study consists of patients with many different histologies due to the rarity of many pediatric metastatic tumors. In the literature, most authors have evaluated pulmonary metastasectomies, which compromise various types of tumors $[3,13,14,15]$.

\section{Conclusions}

The indications for pulmonary metastasectomy vary greatly in pediatric patients. Multidisciplinary treatment involving pediatric oncologists, surgeons, and radiation oncologists is necessary to obtain positive results in children who have pulmonary metastases of oncological diseases. Our retrospective study contributes to the increasing amount of data pertaining to both the indications for and outcomes of this procedure. Non-anatomic wedge resection is an ideal technique for pulmonary metastasectomy due to the preservation of lung parenchyma and decreased blood loss.

\section{Competing interests}

The authors declare that they have no competing interests.

\section{Authors' contributions}

BE carried out the retrospective analysis and drafted the manuscript. FGS and EK participated in the design of the study and performed the statistical analysis. AC and TS edited the paper. All authors read and approved the final manuscript.

\section{Funding}

The authors received no financial support for research or for authorship of this article.

\section{Author details}

${ }^{1}$ Istanbul Faculty of Medicine, Department of Pediatric Surgery, Istanbul University, Oguz Goker Caddesi, 5. Gazeteciler Sitesi, C-1 Blok No. 36, Akatlar Mahallesi, Besiktas, Istanbul, Turkey. ${ }^{2}$ Department of Pediatric Hematology and Oncology, Istanbul University, Institute of Oncology, Istanbul, Turkey. 
Received: 28 July 2015 Accepted: 26 January 2016

Published online: 02 February 2016

\section{References}

1. Dongel I, Ozkan B, Tanju S, Toker A. Pulmonary sublobar resections in pediatric patients. Göğüs Kalp Damar Cerrahisi Dergisi. 2014;22(1):99-103.

2. Harting MT, Blakely ML, Jaffe N, Cox Jr CS, Hayes-Jordan A, Benjamin RS, et al. Long-term survival after aggressive resection of pulmonary metastases among children and adolescents with osteosarcoma. J Pediatr Surg. 2006;41:194-9.

3. Tronc F, Conter C, Marec-Berard P, Bossard N, Remontet L, Orsini A, et al. Prognostic factors and long-term results of pulmonary metastasectomy for pediatric histologies. Eur J Cardiothorac Surg. 2008;34:1240-6.

4. Rodriguez MA, Lugo-Vicente H. Pulmonary metastasectomy for children with malignant tumors. Bol Asoc Med P R. 2012;104:35-40.

5. Harting MT, Blakely ML. Management of osteosarcoma pulmonary metastases. Semin Pediatr Surg. 2006;15:25-9.

6. Parida L, Fernandez-Pineda I, Uffman J, Davidoff AM, Gold R, Rao BN. Thoracoscopic resection of computed tomography-localized lung nodules in children. J Pediatr Surg. 2013:48:750-6.

7. Han KN, Kang CH, Park IK, Kim YT. Thoracoscopic resection of solitary lung metastases evaluated by using thin-section chest computed tomography: is thoracoscopic surgery still a valid option? Gen Thorac Cardiovasc Surg. 2013;61:565-70.

8. Kayton ML, Huvos AG, Casher J, Abramson SJ, Rosen NS, Wexler LH, et al. Computed tomographic scan of the chest underestimates the number of metastatic lesions in osteosarcoma. J Pediatr Surg. 2006;41:200-6.

9. Letourneau PA, Xiao L, Harting MT, Lally KP, Cox Jr CS, Andrassy RJ, et al. Location of pulmonary metastasis in pediatric osteosarcoma is predictive of outcome. J Pediatr Surg. 2011:46:1333-7.

10. Heij HA, Vos A, de Kraker J, Voûte PA. Prognostic factors in surgery for pulmonary metastases in children. Surgery. 1994;115:687-93.

11. Tanaka Y, Maniwa Y, Nishio W, Yoshimura M, Okita Y. The optimal timing to resect pulmonary metastasis. Eur J Cardiothorac Surg. 2008;33:1135-8.

12. Torre W, Rodriguez-Spiteri N, Sierrasesumaga L. Current role for resection of thoracic metastases in children and young adults—-do we need different strategies for this population? Thorac Cardiovasc Surg. 2004;52:90-5.

13. Abel RM, Brown J, Moreland B, Parikh D. Pulmonary metastasectomy for pediatric solid tumors. Pediatr Surg Int. 2004;20:630-2.

14. Häcker FM, von Schweinitz D, Gambazzi F. The relevance of surgical therapy for bilateral and/or multiple pulmonary metastases in children. Eur J Pediatr Surg. 2007;17:84-9.

15. Kayton ML. Pulmonary metastasectomy in pediatric patients. Thorac Surg Clin. 2006;16:167-83.

\section{Submit your next manuscript to BioMed Central and we will help you at every step:}

- We accept pre-submission inquiries

- Our selector tool helps you to find the most relevant journal

- We provide round the clock customer support

- Convenient online submission

- Thorough peer review

- Inclusion in PubMed and all major indexing services

- Maximum visibility for your research

Submit your manuscript at www.biomedcentral.com/submit
Biomed Central 